\section{References}

BAtChELder, H. P. 1986. Phytoplankton balance in the oceanic subarctic Pacific: Grazing impact of Metridia pacifica. Mar. Ecol. Prog. Ser. 34: 213-225.

Bollens, S. M., AND B. W. Frost. 1989. Zooplanktivorous fish and variable diel vertical migration in the marine planktonic copepod Calanus pacificus. Limnol. Oceanogr. 34: 1072-1083. - AND - 1991. Ovigerity, selective predation, and variable diel vertical migration in Euchaeta elongata (Copepoda: Calanoida). Oecologia 87: 155-161.

DagG, M. J., B. W. Frost, AND J. Newton. 1998. Diel vertical migration and feeding in adult female Calanus pacificus, $\mathrm{Me}$ tridia lucens and Pseudocalanus newmani during a spring bloom in Dabob Bay, a fjord in Washington USA. J. Mar. Syst. 15: 503-509.

Dawidowicz, P., J. Pijanowska, And K. Ciechomski. 1990. Vertical migration of Chaoborus larvae is induced by the presence of fish. Limnol. Oceanogr. 35: 1631-1637.

De Robertis, A., J. S. JafFe, and M. D. Ohman. 2000. Sizedependent predation risk and the timing of vertical migration in zooplankton. Limnol. Oceanogr. 45: 1838-1844.

FiKsen, O., AND F. CARLotTi. 1998. A model of optimal life history and diel vertical migration in Calanus finmarchicus. Sarsia 83: 129-147.

HAYs, G. C. 1995. Ontogenetic and seasonal variation in the diel vertical migration of the copepods Metridia lucens and Metridia longa. Limnol. Oceanogr. 40: 1461-1465.

HIRCHE, H. J. 1996. Diapause in the marine copepod, Calanus finmarchicus-a review. Ophelia 44: 129-143.

HunTley, M. E., AND E. R. BROOKS. 1982. Effects of age and food availability on diel vertical migration of Calanus pacificus. Mar. Biol. 71: 23-31.

IRIGOIEN, X., AND OTHERS. 1998. A high frequency time series at weathership M, Norwegian Sea, during the 1997 spring bloom: Feeding of adult female Calanus finmarchicus. Mar. Ecol. Prog. Ser. 172: 127-137.

JóNASDóTTIR, S. H. 1999. Lipid content of Calanus finmarchicus during overwintering in the Faroe-Shetland Channel. Fish. Oceanogr. 8: 61-72.

Longhurst, A. R., AND W. G. Harrison. 1989. The biological pump: Profiles of plankton production and consumption in the upper ocean. Prog. Oceanogr. 22: 47-123.
McLeroy-Etheridge, S. L., And G. B. McManus. 1999. Food type and concentration affect chlorophyll and carotenoid destruction during copepod feeding. Limnol. Oceanogr. 44: 2005-2011.

Miller, C. B., C. A. Morgan, F. G. Prahl, and M. A. Sparrow. 1998. Storage lipids of the copepod Calanus finmarchicus from Georges Bank and the Gulf of Maine. Limnol. Oceanogr. 43: 488-497.

Naulleau, G., And X. Bonnet. 1996. Body condition threshold for breeding in a viviparous snake. Oecologia 107: 301-306.

NeILL, W. E. 1990. Induced vertical migration in copepods as a defence against invertebrate predation. Nature 345: 524-526.

Ohman, M. D., A. V. Drits, M. E. Clarke, and S. Plourde. 1998. Differential dormancy of co-occurring copepods. Deep-Sea Res. II 45: 1709-1740.

OsGood, K. E., AND B. W. Frost. 1994. Comparative life histories of three species of planktonic calanoid copepods in Dabob Bay, Washington. Mar. Biol. 118: 627-636.

PEARRE, S. JR. 1979. Problems of detection and interpretation of vertical migration. J. Plankton Res. 1: 29-44.

Reiss, C. S., I. A. McLaren, And P. A. Avendano. 1999. Utility of storage lipid volumes in inferring recent trophic history of copepods. Can. J. Fish. Aquat. Sci. 56: 2444-2449.

RingelberG, J. 1999. The photobehavior of Daphnia spp. as a model to explain diel vertical migration in zooplankton. Biol. Rev. Camb. Philos. Soc. 74: 397-423.

Sekino, T., AND N. YamamuRA. 1999. Diel vertical migration of zooplankton: Optimum migrating schedule based on energy accumulation. Evol. Ecol. 13: 267-282.

SPEAKMAN, J. R. 1991. Why do insectivorous bats in Britain not fly in daylight more frequently? Funct. Ecol. 5: 518-524.

TARLING, G. A., J. CuZIN-Roudy, AND F. BuChHOLZ. 1999. Vertical migration behavior in the northern krill Meganyctiphanes norvegica is influenced by moult and reproductive processes. Mar. Ecol. Prog. Ser. 190: 253-262.

ZARET, T. M., AND J. S. Suffern. 1976. Vertical migration in zooplankton as a predator avoidance mechanism. Limnol. Oceanogr. 21: $804-813$.

Received: 6 June 2001

Accepted: 21 August 2001

Amended: 6 September 2001

\title{
Daphnia food limitation in three hypereutrophic Dutch lakes: Evidence for exclusion of large-bodied species by interfering filaments of cyanobacteria
}

Abstract-The Loosdrecht Lakes comprise three shallow, hypereutrophic lakes in The Netherlands. Research conducted over the past two decades suggests that absence of large-bodied Daphnia from these lakes can be explained by size-specific effects of both poor food quality and predatory mortality. The phytoplankton is dominated by filamentous cyanobacteria, which interfere with the feeding of large-bodied Daphnia. Moreover, dense populations of planktivorous fish are expected to feed selectively on larger prey. More recent research, however, suggests that the growth of the small native Daphnia species, Daphnia cucullata, is limited by low dietary phosphorus $(\mathrm{P})$. In this study, we compared the growth and feeding rates of four Daphnia taxa representing a gradient in body size. In each of 10 growth experiments, native $D$. cucullata feeding in natural seston exhibited improved growth in response to additions of phosphate and the P-rich cyanobacterium Synechococcus. The two largest species, Daphnia magna and Daphnia galeata, however, failed to grow in natural seston, even when the seston was supplemented with phosphate, Synechococcus, or Scenedesmus. A D. galeata $\times$ cucullata hybrid exhibited weak growth in natural seston and no response to the supplements. Feeding experiments with polystyrene beads show that feeding inhibition in natural seston increased markedly with increased Daphnia size. Our results verify that Daphnia differing in size face different food quality constraints. The growth of native D. cucullata (adult size 0.6$0.8 \mathrm{~mm}$ ) is reduced by $\mathrm{P}$ deficiency, whereas larger Daphnia appear to be excluded by interfering filaments of cyanobacteria. 
The dominance of small-bodied zooplankton in eutrophic lakes is often attributed to size-selective predation by planktivorous fish. Fish predation can be especially intense in shallow lakes where zooplankton lack a deep-water refuge (Tessier and Welser 1991). Food limitation is also important in eutrophic lakes. Despite high food abundance, food quality is often poor, especially in lakes dominated by cyanobacteria. Laboratory experiments show that cyanobacteria can be poor quality foods for zooplankton for a variety of reasons, including toxicity, digestion resistance, difficulties in handling and ingesting filaments and colonies, and nutritional inadequacy (see reviews by Lampert 1987a; de Bernardi and Giussani 1990; Brett and Müller-Navarra 1997). However, despite evidence from laboratory experiments, the roles of these various food quality mechanisms in nature are poorly understood (reviewed by Haney 1987). Filamentous cyanobacteria can inhibit the feeding of daphnids, thereby reducing the collection and ingestion of more nutritious resources. Since feeding inhibition increases with increasing Daphnia body size, both feeding inhibition and fish predation favor small-bodied daphnids in eutrophic lakes (reviewed by Gliwicz 1990a).

Both poor food quality and fish predation are considered to have strong impacts on the zooplankton communities of our three shallow (mean depths $=1.45-1.85 \mathrm{~m}$ ), interconnected study lakes (reviewed by DeMott and Gulati 1999). The phytoplankton of all three lakes is dominated by cyanobacteria year-round, mainly Oscillatoria limnetica and the prochlorophyte Prochlorothrix hollandica. Together, these two filamentous forms comprise, on average, about $90 \%$ of the algal mass in suspension and often exceed $10^{5}$ filaments $\mathrm{ml}^{-1}$ (Van Tongeren et al. 1992). Fish are very abundant (about $300 \mathrm{~kg} \mathrm{ha}^{-1}$ ) and are dominated by stunted, planktivorous bream (Abramis brama; Lammens et al. 1992). The zooplankton in all three lakes is dominated by small species, including Bosmina spp. (longirostris and coregoni), Chydorus sphaericus, cyclopoid copepods, and rotifers (Gulati et al. 1992). The genus Daphnia is represented almost exclusively by the smallest Eurasian species, Daphnia cucullata. Daphnia galeata, which is common in other shallow hypereutrophic Dutch lakes, is conspicuous by its absence.

Laboratory and field experiments support the notion that the combined effects of interfering filaments and fish predation are responsible for the absence of larger Daphnia species in the Loosdrecht Lakes. A series of laboratory experiments showed that Daphnia magna was able to grow and reproduce in seston from Lake Loosdrecht only after the filament concentration was reduced by dilution (Davidowicz et al. 1988). The lack of success of a biomanipulation project in Lake Breukeleveen was attributed to high densities of filamentous cyanobacteria (Van Donk et al. 1990). Further experiments showed that $D$. galeata could flourish in mesocosms in Lake Breukeleveen when the fish abundance was reduced to about $15 \%$ of the lake density (Van Donk et al. 1994). However, in addition to the fish reduction, the concentration of cyanobacteria filaments declined in the mesocosms, presumably due to reduced turbulence. Thus, a reduction in both fish and filaments may have been necessary for the successful establishment of $D$. galeata.

More recently, however, DeMott and Gulati (1999) found a strong inverse relationship between the abundance of $D$. cucullata and the phosphorus (P) content of seston, using a 9-yr data set from the Loosdrecht Lakes. This finding suggests an additional explanation for the poor food quality of lake seston. Thus, it becomes important to consider how the effects of interfering filaments might interact with $\mathrm{P}$ deficiency. High concentrations of filaments reduce feeding rates on alternative food resources, leading to energy limitation (Gliwicz 1990a). Theory predicts an interaction between energy limitation and P limitation (Sterner 1997). When available energy is very low, near the threshold food concentration for individual growth, most assimilated carbon is respired, and P-sufficient and P-deficient resources support equivalent, very low growth rates (Sterner and Robinson 1994). Thus, strong energy limitation due to feeding inhibition should prevent P limitation.

Here, we compare the growth and feeding rates of the small native D. cucullata and three larger Daphnia taxa feeding in the filament-rich seston of the Loosdrecht Lakes. We consider whether size-specific feeding inhibition, caused by filaments of cyanobacteria, can account for the absence of large-bodied Daphnia species in the Loosdrecht Lakes. An analysis of the effects of dietary $\mathrm{P}$ deficiency on the population dynamics, growth, and $\mathrm{P}$ balance of $D$. cucullata in all three lakes is presented elsewhere (DeMott et al. in press). That study describes the methods for collecting field samples and includes data on the seasonal dynamics of seston abundance and the seston $\mathrm{C}: \mathrm{P}$ ratio in all three lakes.

Our growth and feeding experiments used D. cucullata isolated from Lake Breukeleveen and clonal cultures of three larger taxa from the Center of Limnology culture collection, including D. magna, D. galeata, and a D. galeata $\times$ cucullata hybrid. The hybrid clone was the product of a cross between the two parental species performed in the laboratory (K. Schwenk pers. comm.). Laboratory clones were grown in filtered water from Lake Maarsseveen and fed a high concentration (1-2 $\mathrm{mg} \mathrm{C} \mathrm{L}^{-1}$ ) from P-sufficient cultures (molar $\mathrm{C}: \mathrm{P}=80$ ) of the green alga Scenedesmus obliquus. The Daphnia culturing, the growth assays, and the feeding experiments were carried out in the same temperature-controlled room at $19^{\circ} \mathrm{C}$ under dim light. Methods for culturing algae and measuring their concentration followed DeMott et al. (1998).

We conducted a total of 21 growth assays between 7 June and 16 July 1999, including separate experiments with seston from each of the three lakes. Growth assays tested the ability of juvenile Daphnia to grow on natural seston or natural seston supplemented with phosphate or with the Prich cyanobacterium Synechococcus. In addition, we measured the growth of each cohort with a high concentration ( $2 \mathrm{mg} \mathrm{C} \mathrm{L}^{-1}$ ) of the green alga Scenedesmus in filtered $(\mathrm{GF} /$ F) water from Lake Breukeleveen. Scenedesmus alone was expected to support high growth rates. The 4-d growth assays were run in beakers, with food and medium exchanged after $2 \mathrm{~d}$. Growth assays for the three larger taxa were begun with a cohort of 1-3-d-old animals born during a 24-h period. We did not have a laboratory culture of $D$. cucullata. Therefore, we collected D. cucullata from Lake Breukeleveen and isolated cohorts of field-collected small juveniles under a dissecting microscope using a pipette. 
Growth rates were calculated from changes in mass during the 4-d experiments. Three samples were used to estimate the initial mass, with each sample containing $3 \mathrm{D}$. magna, 5-8 D. galeata, 6-8 D. galeata $\times$ cucullata, or 10-15 D. cucullata. The number of animals and the size of the experimental beakers were adjusted to reflect the large differences in animal size and expected feeding rates. Beakers contained 3 D. magna in $500 \mathrm{ml}$ of medium, 6-8 D. galeata or D. galeata $\times$ cucullata in $300 \mathrm{ml}$, or 10-12 D. cucullata in 150 ml. Each experimental treatment included three replicate beakers. The number of survivors, their lengths, and the number of eggs were recorded at the end of each 4-d experiment. Methods for processing the samples and calculating growth followed DeMott et al. (1998) (see DeMott et al. [2001] for further details on the growth assay methods).

The Daphnia growth assays included four treatments: (1) natural seston, (2) natural seston $+100 \mu \mathrm{g} \mathrm{P} \mathrm{L} \mathrm{P}^{-1}$ as phosphate, (3) natural seston $+2 \mathrm{mg} \mathrm{C} \mathrm{L}^{-1}$ of Synechococcus, and (4) filtered lake water with $2 \mathrm{mg} \mathrm{C} \mathrm{L}^{-1}$ of Scenedesmus. One series of experiments also included an additional treatment with seston supplemented with $2 \mathrm{mg} \mathrm{C} \mathrm{L}^{-1}$ of Scenedesmus. Natural seston was filtered through a $33-\mu \mathrm{m}$ screen to remove zooplankton. The phosphate and Synechococcus treatments contained the same $\mathrm{P}$ concentration, and both were designed to reduce the $\mathrm{C}: \mathrm{P}$ of the total diet to $<200$ (molar), below the threshold for $\mathrm{P}$ limitation in Daphnia (Sterner and Hessen 1994).

Two series of feeding experiments were carried out between 21 and 27 July 1999. Feeding experiments tested the clearance rates of each taxon with Scenedesmus (1 mg C $\mathrm{L}^{-1}$ ) in lake water filtered to remove grazable particles (GF/ F filter) and in coarsely filtered seston $(33 \mu \mathrm{m})$ from Lake Breukeleveen. The concentration of filaments in the coarsely filtered lake seston was estimated using an inverted microscope. Clearance rates were estimated using polystyrene beads (DeMott 1986). Animals of the three larger taxa were grown in cohorts in the laboratory. We used two or three size classes of each taxon, including 1-d-old juveniles, older juveniles, and primiparous adults. D. cucullata included groups of early instar juveniles and adults collected from Lake Breukeleveen. The mean individual mass for each size class was estimated by weighing a subset of animals isolated about $3 \mathrm{~h}$ before each feeding experiment.

Animals were acclimated in the feeding suspensions for 2-3 h before each feeding trial. A new stock solution of beads (6 $\mu \mathrm{m}$; Duke Scientific) was prepared each day and counted with a Coulter Multisizer II electronic particle counter. Beads were mixed into the feeding suspension, and the animals were allowed to feed for $6 \mathrm{~min}$. At the end of each feeding trial, the animals were filtered onto a screen, anesthetized with carbonated water, and preserved in $95 \%$ ethanol. The concentration of beads was varied with animal size and food concentration to reduce variation in the numbers of beads ingested between species and treatments. For trials with Scenedesmus (1 $\left.\mathrm{mg} \mathrm{C} \mathrm{L}^{-1}\right)$, the bead concentration ranged from 1,000 beads $\mathrm{ml}^{-1}$ for D. magna to 3,000 beads $\mathrm{ml}^{-1}$ for D. cucullata. For animals feeding in seston from Lake Breukeleveen (seston concentration about $8 \mathrm{mg} \mathrm{C} \mathrm{L}^{-1}$ ), the bead concentration ranged from 4,000 beads $\mathrm{ml}^{-1}$ for $D$. magna to 10,000 beads $\mathrm{ml}^{-1}$ for $D$. cucullata. The volumes
Table 1. Ranges of length and mass of Daphnia spp. in growth assays. Final mass is from the Scenedesmus treatment, a mixture of the last juvenile and the first adult instars. Adult length is from measurements of egg-bearing females. Data are for 5 experiments with each of $D$. magna and $D$. galatea, 1 experiment with a $D$. galatea $\times$ cucullata hybrid $(D . g \times c)$, and 10 experiments with D. cucullata.

\begin{tabular}{lccccc}
\hline \hline & \multicolumn{2}{c}{ Mass $(\mu \mathrm{g})$} & & \multicolumn{2}{c}{ Length $(\mathrm{mm})$} \\
\cline { 2 - 3 } \cline { 5 - 6 } & Initial & Final & & Initial & Adult \\
\hline D. magna & $13-45$ & $140-332$ & & $0.98-1.70$ & $2.68-3.00$ \\
D. galatea & $3.6-5.2$ & $21-31$ & & $0.73-0.90$ & $1.46-1.71$ \\
D. g $\times c$ & $3.3-3.8$ & $20-21$ & & $0.67-0.69$ & $1.12-1.44$ \\
D. cucullata & $0.7-0.9$ & $2.7-4.1$ & & $0.42-0.46$ & $0.59-0.73$ \\
\hline
\end{tabular}

of the feeding suspensions were the same as used in the growth assays. Three replicate beakers were used for each species, size class, and treatment.

To estimate clearance rates for beads, animals from a feeding trial were placed on a microscope slide, and body tissues were dissolved using several drops of a tissue solubilizer (TS-1; Research Products International). The number of beads in each animal was counted using a compound microscope ( $\times 100$ and $\times 400$ magnification), and the length of each animal was measured with an ocular micrometer. We predicted that clogging of the feeding mechanism and filament rejection would cause an increase in the proportion of beads that were collected in the feeding chamber but not swallowed. We therefore distinguished beads in the feeding chamber and food grove from beads in the gut. Mean body length and clearance rates were calculated for each beaker by calculating averages across individuals. Some animals failed to feed or fed at very low rates. Data from individuals with feeding rates $<10 \%$ of the mean for a trial were excluded from further calculations.

The Daphnia species differed markedly in body size, ranging from juvenile $D$. cucullata weighing $<1 \mu \mathrm{g}$ dry mass per individual to adult D. magna $>300 \mu \mathrm{g}$ (Table 1). The $D$. galeata $\times$ cucullata hybrid was intermediate in size between the two parental species but was more similar to the larger parent, D. galeata. The largest D. cucullata encountered in field samples was about $0.80 \mathrm{~mm}$ in total length.

Periodic observations with an inverted microscope showed that filamentous prokaryotes dominated the phytoplankton throughout the study period. The concentration of filamentous prokaryotes was estimated for two coarsely filtered $(33 \mu \mathrm{m})$ samples from each lake taken during July. Estimates ranged from 1.2 to $2.2 \times 10^{5}$ filaments $\mathrm{ml}^{-1}$. Most filaments were thin (1.5-3 $\mu \mathrm{m}$ in diameter), and the mean length was about $80 \mu \mathrm{m}$. Visual observations and microscope counts showed that the $33-\mu \mathrm{m}$ screen retained negligible numbers of filaments. Weekly estimates of seston passing through a $33-\mu \mathrm{m}$ screen from each lake ranged from 5.7 to $8.9 \mathrm{mg} \mathrm{C} \mathrm{L}^{-1}$ (DeMott et al. 2001). The seston $\mathrm{C}$ : $\mathrm{P}$ ratio ranged from about 350 to 500 for all three lakes. Estimates of the filament concentration in the coarsely filtered seston used in the feeding experiments ranged from 1.9 to $2.2 \times$ $10^{5}$ filaments $\mathrm{ml}^{-1}$.

Figure 1 shows the results of the first growth experiment, 


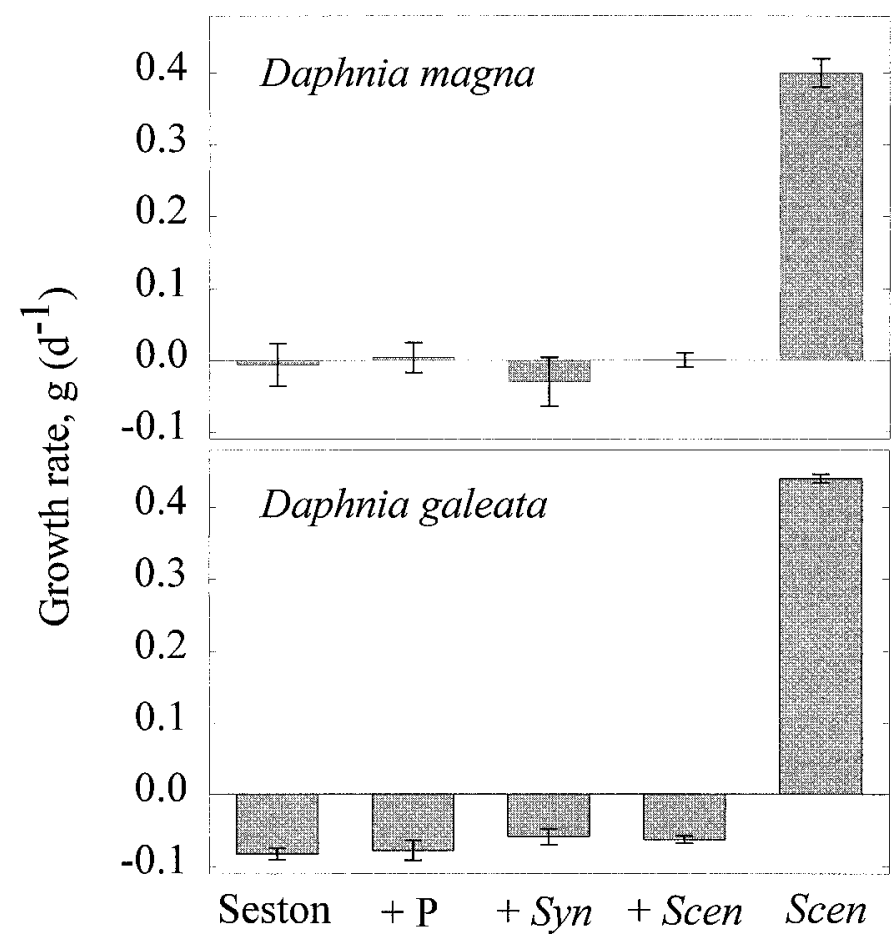

Fig. 1. The growth (per day) of D. magna and D. galeata in seston from Lake Vuntus, in seston supplemented with phosphate $(+\mathrm{P})$, Synechococcus $(+$ Syn $)$, or Scenedesmus $(+$ Scen $)$, and in filtered lake water with Scenedesmus (Scen). Data show means \pm standard error for three replicate beakers for an experiment run from 7 to 11 June 1999.

with D. magna and D. galeata feeding in seston from Lake Vuntus, in seston supplemented with phosphate, Synechococcus, or Scenedesmus $\left(2 \mathrm{mg} \mathrm{C} \mathrm{L}^{-1}\right)$, and in filtered lake water with the same concentration of Scenedesmus alone. Growth was high with Scenedesmus alone but was zero or negative in each treatment with natural seston. The remaining growth experiments used the same experimental design as the first experiment (Fig. 1), except that they lacked a treatment with seston plus Scenedesmus. Since the results for the larger taxa did not vary over time or between lakes, we summarized all 21 growth assays in Fig. 2. All four taxa exhibited high growth rates with Scenedesmus alone. However, growth in treatments with natural seston varied with body size. D. magna and $D$. galeata lost mass in natural seston, the hybrid showed low growth, and D. cucullata showed moderate growth. The three larger taxa showed no response to the supplements (one-way ANOVA, each of 11 tests, $P>0.05$ ). In contrast, $D$. cucullata exhibited improved growth in response to the phosphate and Synechococcus supplements in each experiment (one-way ANOVA, $P<0.05$ for each of 10 tests). For $D$. cucullata, mean growth in natural seston supplemented with Synechococcus was $85 \%$ of the growth rate in Scenedesmus alone.

$D$. magna and D. galeata growing in treatments with natural seston experienced variable mortality $(0-60 \%)$, with at least one D. magna or two D. galeata surviving in each beaker. At the end of the experiment, survivors of these two species in the seston treatments were often found at the bot-

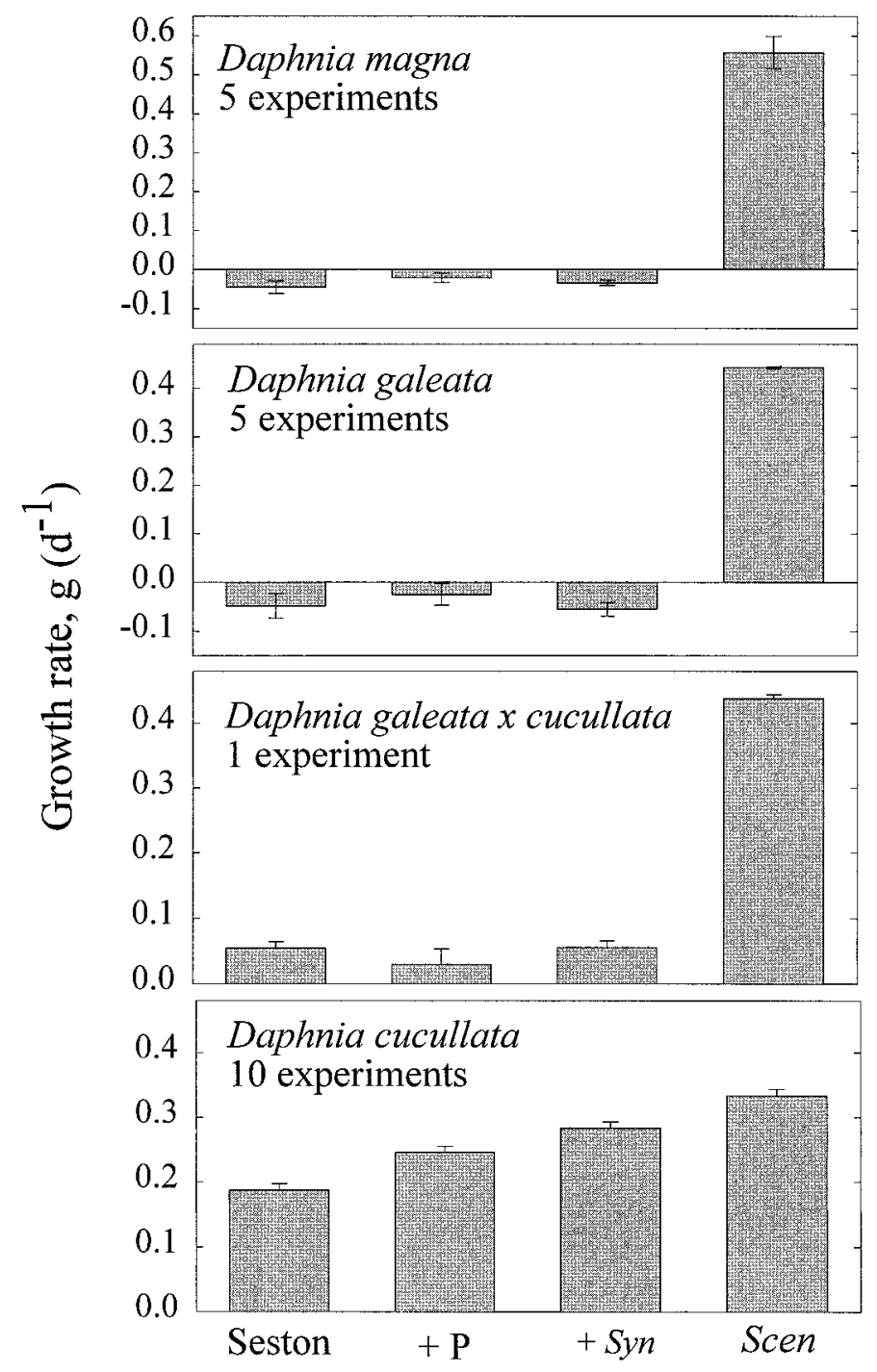

Fig. 2. The growth (per day) of four Daphnia taxa in seston, in seston supplemented with phosphate $(+\mathrm{P})$ or Synechococcus $(+S y n)$, and in filtered lake water with Scenedesmus (Scen). Data show overall means \pm standard error for five experiments each with D. magna and D. galeata and 10 experiments with D. cucullata. Data for $D$. galeata $\times$ cucullata show means \pm standard error for three replicate beakers for a single experiment conducted with seston from Lake Breukeleveen. Data for each of the other three taxa include separate experiments conducted with seston from each of the three Loosdrecht Lakes. Note differences in scale between species.

tom of the beakers, barely moving. Lower survival may have created biases, if smaller individuals were more likely to die. Thus, growth on natural seston by these large taxa may have been overestimated. However, the key point is the lack of growth by the two larger Daphnia species in each treatment with natural seston. Survivorship was high $(>90 \%)$ for all four taxa feeding in Scenedesmus alone and for the hybrid and $D$. cucullata in all treatments.

Feeding data are expressed as functions of body length and carbon. Carbon was assumed to equal $50 \%$ of body mass. The proportion of beads in the gut was about $90 \%$ for animals feeding on Scenedesmus alone and showed little or 

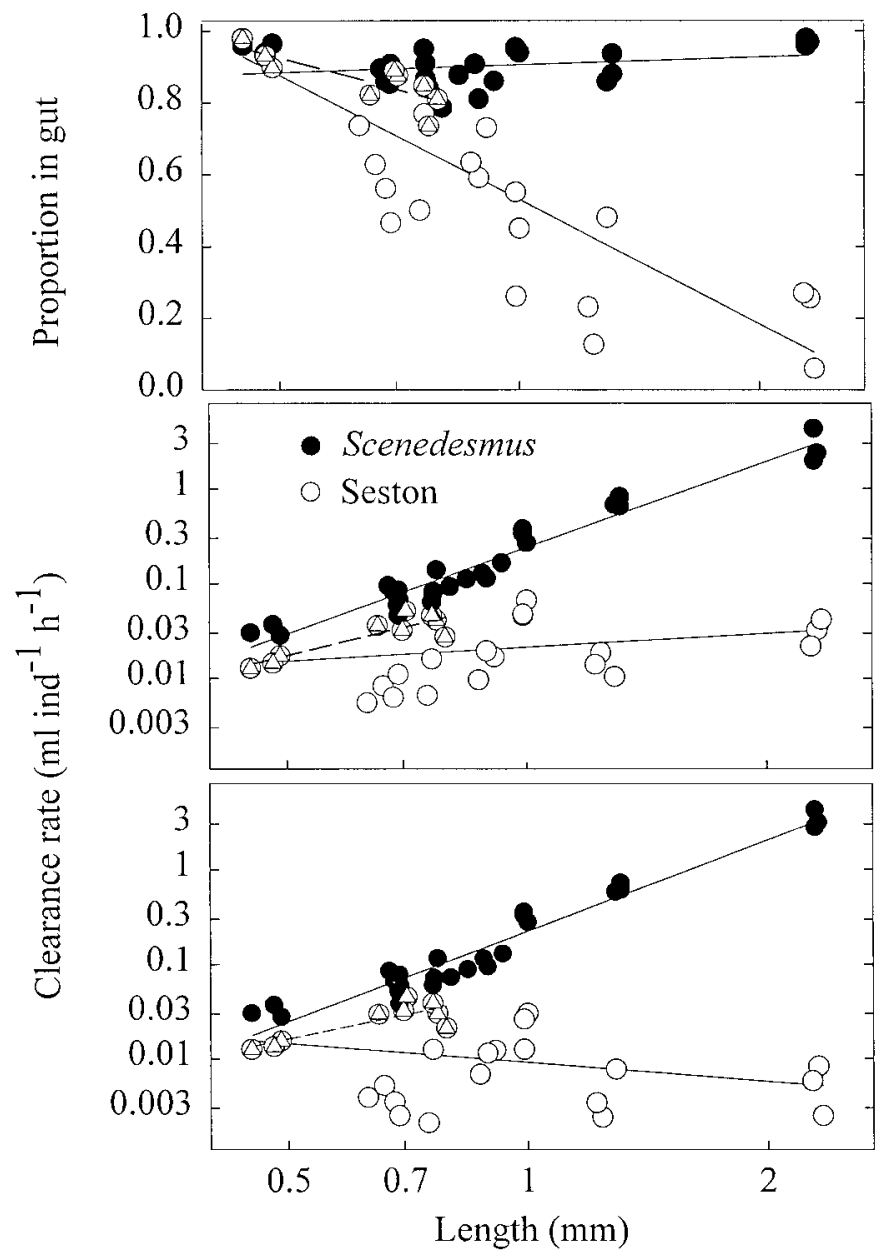

Fig. 3. Relationships between body length and feeding rates on $6-\mu \mathrm{m}$ beads for four taxa of Daphnia feeding in seston from Lake Breukeleveen or in filtered lake water with Scenedesmus (1 mg C $\mathrm{L}^{-1}$ ). Regressions were calculated for all four taxa combined (circles and solid lines) and for D. cucullata alone (triangles and dashed line). The upper panel shows the proportion of beads in the gut of the total number collected. Clearance rates (milliliters per individual per day) were calculated for all beads collected (middle panel) and for beads in the gut (lower panel). Each data point is the mean for 3-30 animals from a beaker.

no variation with body length (Fig. 3, upper panel; $r^{2}=0.07$, $P=0.18$ ). In contrast, the proportion of beads in the gut declined with increasing body size for all species feeding in natural seston (Fig. 3, upper panel; $r^{2}=0.69, P<0.001$ ). The proportion of beads in the gut also declined with increasing body size for $D$. cucullata feeding in seston $\left(r^{2}=\right.$ $0.66, P<0.001)$. However, adult $D$. cucullata tended to have a higher proportion of beads in their guts than did juvenile $D$. galeata and $D$. galeata $\times$ cucullata similar in size to the adult $D$. cucullata.

As expected, the clearance rate on Scenedesmus alone increased strongly with increasing body size (Fig. 3, middle panel; Table 2). By contrast, for animals feeding in natural seston, the relationship between clearance rate and body size was weak, even when beads that were collected but not ingested are included (Fig. 3, middle panel; Table 2). When only beads found in the gut are included, the absolute clearance rate declined with increasing body size, although the slope is not significant (Fig. 3, lower panel; Table 2). In contrast to the overall regressions, separate regressions for D. cucullata exhibited positive slopes (Fig. 3; Table 2). Adult $D$. cucullata tended to show a higher clearance rate than juvenile $D$. galeata and $D$. galeata $\times$ cucullata similar in size to the adult $D$. cucullata. No species-specific responses were noted among the three larger taxa. Clearance rates for juvenile $D$. magna overlapped with values for adults of D. galeata and the hybrid of similar size.

The mass-specific clearance rate (MSCR; $\mathrm{ml} \mathrm{mg} \mathrm{C}^{-1} \mathrm{~d}^{-1}$ ) on Scenedesmus showed little or no change over a 100 -fold change in body mass (MSCR $=1,104$ Mass $^{0.040}, r^{2}=0.03$ ). Thus, the mean daily ration of Scenedesmus across all four taxa was about $110 \%$ of body carbon. In contrast to data for Scenedesmus, the MSCR in natural seston declined sharply with increasing size (MSCR $=619 \mathrm{M}^{-0.775}, r^{2}=0.68, P<$ 0.001 ). The predicted MSCR of juvenile $D$. cucullata (about $0.5 \mu \mathrm{g} \mathrm{C}$ per individual) was about 40 times higher than that for a juvenile D. magna 100 -fold greater in mass.

Our experiments show a clear distinction between the small native D. cucullata and three larger Daphnia taxa in their abilities to feed and grow on natural seston from the three Loosdrecht Lakes. In support of the P-limitation hypothesis, D. cucullata showed improved growth with phosphate and Synechococcus supplements. The role of P limitation in constraining the growth and abundance of $D$. cucullata in the Loosdrecht Lakes gains further support from a 9-yr field study (DeMott and Gulati 1999) and from a study that includes data on the population dynamics and $\mathrm{P}$ balance of D. cucullata, as well as a detailed analysis of the growth assays for that species (DeMott et al. 2001).

In contrast to $D$. cucullata, D. magna and $D$. galeata failed to grow in natural seston even when P, Synechococcus, or Scenedesmus was added. The lack of response to the supplements is strong evidence that the poor growth of these taxa was not due to a nutritional deficiency. $\mathrm{P}$ limitation can be ruled out by the lack of response to phosphate and P-rich Synechococcus. Moreover, since Scenedesmus is a good food by itself, the lack of growth when seston was supplemented with Scenedesmus further demonstrates that poor growth in seston alone was due to the presence of an inhibiting factor rather than to a deficiency in nutrients or energy per se. Excellent growth in filtered water from Lake Breukeleveen with Scenedesmus provides evidence against any dissolved poisons or inhibitors. Our findings differ with those of Müller-Navarra et al. (2000), who argued that the poor growth of D. magna in a lake dominated by Oscillatoria was due to a deficiency in essential fatty acids.

Although all four Daphnia species fed in seston above the $\mathrm{C}$ : P threshold for P limitation, only D. cucullata shows evidence of P-limited growth. As noted in the introduction, strong energy limitation can prevent P limitation (Sterner 1997). Thus, these results are consistent with stoichiometric theory, as long as one assumes that the three larger taxa experienced strong energy limitation.

Our feeding experiments support the hypothesis that the three larger taxa experienced strong energy limitation due to feeding interference. The feeding rate on natural seston did 
Table 2. The results of regressions, where clearance rate $\left(\mathrm{CR}, \mathrm{ml} \mathrm{ind}^{-1} \mathrm{~h}^{-1}\right)$ is expressed as a power function of length (mm) of the form CR $=a$ Length $^{b}$. Animals were fed in Scenedesmus alone $\left(1 \mathrm{mg} \mathrm{C} \mathrm{L}^{-1}\right)$ or in seston from Lake Breukeleveen. Regressions were calculated separately for all beads and for beads found in the gut. Regressions were run for all four species combined and for $D$. cucullata alone. Each sample $(n)$ is the mean length and clearance rate for a beaker of animals.

\begin{tabular}{|c|c|c|c|c|c|c|c|c|c|}
\hline & \multicolumn{5}{|c|}{ All beads } & \multicolumn{4}{|c|}{ Beads in gut } \\
\hline \multicolumn{10}{|l|}{ Scenedesmus } \\
\hline D. cucullata & 9 & 0.144 & 2.00 & 0.95 & 0.001 & 0.113 & 1.69 & 0.90 & 0.001 \\
\hline \multicolumn{10}{|l|}{ Seston } \\
\hline All species & 27 & 0.021 & 0.48 & 0.09 & 0.13 & 0.009 & -0.67 & 0.09 & 0.12 \\
\hline
\end{tabular}

not increase with increasing length, even though the four species represent a wide range in length and mass. This lack of a relationship between body size and feeding rate means that the energy demands of the larger species would not be met even if assimilation efficiency were high. In contrast, all four species showed high feeding rates and excellent growth when feeding on Scenedesmus in filtered lake water. When all four species were included in the feeding rate versus body length regression, the exponent $b$ was about 3 for Scenedesmus (Table 2). This value is within the range for various sizes of Daphnia species feeding on readily ingested resources (Lampert 1987b; DeMott 1995).

Comparison of the proportion of beads in the gut provides further support for the notion that the three larger species suffered from clogging of their feeding mechanism and/or increased rejection rates when feeding on natural seston. Although a previous study noted differences between the collection and ingestion of large beads (Bern 1990), our study is the first of which we are aware that shows how beads can be used as an indicator of interfering particles.

Many laboratory experiments have documented size-specific inhibition of feeding and growth in Daphnia by filamentous algae (reviewed by Gliwicz 1990a). Studies by Gliwicz $(1990 a, b)$ and Gliwicz and Lampert (1990) are of special interest because they include D. cucullata in their experiments. The growth of two larger Daphnia species was inhibited by the presence of filaments, while $D$. cucullata showed no growth inhibition and even benefited from the presence of filaments when the Scenedesmus concentration was low (Gliwicz and Lampert 1990). Another study was designed to test the concentration of Aphanizomenon filaments where the growth rate of each of four Daphnia species approached zero, despite a high concentration of Scenedesmus (Gliwicz 1990b). D. magna reached a zero-growth threshold at about 5,000 filaments $\mathrm{ml}^{-1}$, whereas D. cucullata approached zero growth at about 70,000 filaments $\mathrm{ml}^{-1}$.

Our feeding and growth experiments together suggest that filament concentrations in the Loosdrecht Lakes were above the zero-growth threshold for both $D$. magna and D. galeata. That is, weight loss occurred in natural seston, even when seston was supplemented with phosphate, Synechococcus, or Scenedesmus. Since the D. galeata $\times$ cucullata hybrid showed weak growth in natural seston, the filament concentration was apparently a little below its zero threshold for growth.

In contrast to the three larger taxa, the growth of $\mathrm{D}$. $\mathrm{cu}$ - cullata in seston supplemented with Synechococcus was $85 \%$ of the value for Scenedesmus alone. Three factors may contribute to the low or negligible negative impact of filaments on the feeding and growth of D. cucullata from the Loosdrecht Lakes. First, D. cucullata from the Loosdrecht Lakes is very small, smaller than that grown in the laboratory by Gliwicz (1990b) and Gliwicz and Lampert (1990). A previous study commented on the presence of "dwarf" D. cucullata in lakes with dense fish populations (Hrbacek and Hrbackova-Essova 1960). Second, our feeding studies suggest that adult $D$. cucullata from Lake Breukeleveen may be better at coping with filamentous cyanobacteria than other Daphnia of similar size. However, our feeding and growth experiments were not designed to distinguish between species differences, clonal differences, and possible effects of long-term acclimation. Finally, the condition and size of the filaments may affect the zero threshold. For example, Gliwicz (1990b) showed that filaments of Aphanizomenon in a deteriorating physiological state were better tolerated by Daphnia than were filaments in a good physiological state (see also Gulati et al. 2001). Gliwicz (1990a) also suggested that shorter filaments cause weaker feeding interference than longer filaments. Thus, the thin, relatively short filaments of the Loosdrecht Lakes may be better tolerated than longer, thicker filaments.

Lake Loosdrecht makes an interesting comparison with another well-studied, shallow, highly eutrophic Dutch lake, Lake Tjeukemeer. Both lakes have similar fish communities, and the phytoplankton of both lakes is dominated by Oscillatoria during summer. However, in contrast to Lake Loosdrecht, Lake Tjeukemeer has abundant populations of $D$. galeata and D. galeata $\times$ cucullata hybrids, as well as $D$. cucullata (Boersma and Vijverberg 1994). Although the Oscillatoria biomass is similar, the filament density is about five times higher in Lake Loosdrecht than in Lake Tjeukemeer, which is dominated by a species (Oscillatoria aghardii) that produces thicker, longer filaments (Lammens et al. 1992). Thus, a difference in the species composition of the filamentous cyanobacteria may account for the differences in Daphnia species composition between the two lakes. This assumes that the higher density of filaments in the Loosdrecht Lakes more than offsets the effects of thicker, longer filaments in Lake Tjeukemeer.

Frankly, we were surprised by the strength and consistency of the feeding and growth inhibition experienced by the 
larger Daphnia taxa in natural seston from the Loosdrecht Lakes. These lakes provide an example in which poor individual growth seems sufficient to explain the absence of Daphnia species larger than D. cucullata. Although we did not study fish predation, evidence reviewed in the introductory paragraphs indicates that fish predation is also intense in these lakes. DeMott and Gulati (1999) suggested that the summer disappearance of D. cucullata from individual lakes during certain years was a consequence of consistently strong fish predation and variable $\mathrm{P}$ limitation. Clearly, zooplankton may experience strong fish predation and poor food quality simultaneously.

Our results show that Daphnia species differing in size face different food quality constraints. The possibility that D. cucullata from the Loosdrecht Lakes has adaptations for dealing with high filament concentrations, in addition to small size, may merit further study. Our results provide strong support for earlier studies suggesting that the abundance of $D$. cucullata in the Loosdrecht Lakes is constrained by P limitation (DeMott and Gulati 1999), whereas largebodied Daphnia species are excluded by the interfering effects of filamentous cyanobacteria (Davidowicz et al. 1988). Our results also illustrate the importance of simultaneously testing alternative food quality mechanisms and for taking into account interactions between energy limitation and nutritional deficiencies.

William R. DeMott ${ }^{1}$, Ramesh D. Gulati, and Ellen Van Donk

Netherlands Institute of Ecology

Centre for Limnology

Rijksstraatweg 6

3631 AC Nieuwersluis, The Netherlands

\section{References}

Bern, L. 1990. Post-capture particle size selection by Daphnia cucullata (Cladocera). Limnol. Oceanogr. 35: 923-926.

Boersma, M., And J. ViJverberg. 1994. Seasonal variations in the condition of two Daphnia species and their hybrid in a eutrophic lake: Evidence for food limitation. J. Plankton Res. 16: 1793-1809.

Brett, M. T., And D. C. Müller-Navarra. 1997. The role of highly unsaturated fatty acids in aquatic food-web processes. Freshwater Biol. 38: 483-500.

Davidowicz, P., Z. M. Gliwicz, and R. D. Gulati. 1988. Can Daphnia prevent a blue-green algal bloom in hypereutrophic lakes? A laboratory test. Limnologia 19: 21-26.

DE Bernardi, R., AND G. Giussani. 1990. Are blue-green algae a suitable food for zooplankton? An overview. Hydrobiologia 200/201: 29-41.

DeMotт, W. R. 1986. The role of taste in food selection by freshwater zooplankton. Oecologia 69: 334-340.

. 1995. The influence of prey hardness on Daphnia's selectivity for large prey. Hydrobiologia 307: 127-138.

${ }^{1}$ To whom correspondence should be addressed. Present address: Department of Biology, Indiana-Purdue University, Fort Wayne, Indiana 46805 (demott@ipfw.edu).

Acknowledgments

We thank Klaas Siewertsen for expert assistance in the field and laboratory. Centre for Limnology publication 2809.
AND R. D. Gulati. 1999. Phosphorus limitation in Daphnia: Evidence from a long term study of three hypereutrophic Dutch lakes. Limnol. Oceanogr. 44: 1557-1564.

, AND K. SiEWERTSEN. 1998. Effects of phosphorusdeficient diets on the carbon and phosphorus balance of Daphnia magna. Limnol. Oceanogr. 43: 1147-1161.

, AND E. VAN DONK. 2001. Effects of dietary phosphorus deficiency on the abundance, growth and phosphorus balance of Daphnia cucullata in three hypereutrophic Dutch lakes. Limnol. Oceanogr. 46: 1871-1880.

GLIwicz, Z. M. 1990a. Why do cladocerans fail to control algal blooms? Hydrobiologia 200/201: 83-97.

- 1990b. Daphnia growth at different concentrations of cyanobacteria filaments. Arch. Hydrobiol. 120: 51-65.

-, AND W. LAMPERT. 1990. Food thresholds in Daphnia species in the absence and presence of blue-green filaments. Ecology 71: 691-702.

Gulati, R. D., M. BronkHorst, AND E. VAn Donk. 2001. Feeding in Daphnia galeata on Oscillatoria limnetica and on detritus derived from it. J. Plankton Res. 23: 705-718.

- A. L. Ooms-Wilms, O. F. R. Van Tongeren, G. Postema, AND K. SiewERTSEN. 1992. The dynamics and role of limnetic zooplankton in Loosdrecht lakes (The Netherlands). Hydrobiologia 233: 69-86.

HANEY, J. F. 1987. Field studies on zooplankton-cyanobacteria interactions. NZ J. Mar. Freshwater Res. 21: 467-475.

HrbaCEK, J., AND M. HrbaCKOVA-Esslova. 1960. Fishstock as a protective agent in occurrence of slow developing dwarf species and strains of the genus Daphnia. Int. Rev. Hydrobiol. 45: 355-358.

LAMmens, E.H.R.R., N. BOESEWINKEl-De BRUYN, H. HoOgVeld, AND E. VAN DONK. 1992. P-load, phytoplankton, and fish stock in Loosdrecht Lake and Tjeukemeer: Confounding effects of predation and food availability. Hydrobiologia 233: 87-94.

LAMPERT, W. 1987a. Laboratory studies on zooplankton-cyanobacteria interactions. NZ J. Mar. Freshwater Res. 21: 483-490.

-1987b. Feeding and nutrition in Daphnia. Mem. Ist. Ital. Idrobiol. 45: 143-192.

Müller-Navarra, D. C., M. T. Brett, A. M. Liston, and C. R. GoldmAN. 2000. A highly unsaturated fatty acid predicts carbon transfer between primary producers and consumers. Nature 403: 74-77.

STERnER, R. W. 1997. Modeling interactions of food quality and quantity. Freshwater Biol. 38: 473-482.

, AND D. O. HESSEN. 1994. Algal nutrient limitation and the nutrition of aquatic herbivores. Annu. Rev. Ecol. Syst. 25: 1-29.

- AND J. RoBINSON. 1994. Thresholds for growth in Daphnia magna with high and low phosphorus diets. Limnol. Oceanogr. 39: 261-279.

TESSIER, A. J., AND J. Welser. 1991. Cladoceran assemblages, seasonal succession and the importance of a hypolimnetic refuge. Freshwater Biol. 25: 85-93.

Van Donk, E., M. P. Grimm, R. D. Gulati, P. G. M. Heuts, W. A. De Kloet, AND L. VAN Liere. 1990. First attempt to apply whole-lake food-web manipulation on a large scale in The Netherlands. Hydrobiologia 200/201: 291-301.

, , P. G. M. Heuts, G. Blom, K. Everards, and O. F. R. VAn TONGEREN. 1994. Use of mesocosms in a shallow eutrophic lake to study the effects of different restoration measures. Arch. Hydrobiol. Ergebn. Limnol. 40: 283-294.

Van Tongeren, O. F. R., L. Van Liere, R. D. Gulati, G. PosTEMA, AND P. J. BOESEWINKEL-DE BRUYN. 1992. Multivariate analysis of the plankton communities in the Loosdrecht lakes: Relationship with the chemical and physical environment. Hydrobiologia 233: 105-117.

Received: 20 November 2000 Accepted: 9 July 2001 Amended: 9 August 2001 